\title{
Proliferating trichilemmal cyst with clinical, radiological, macroscopic, and microscopic correlation ${ }^{*}$
}

\author{
Ediel Valerio ${ }^{1}$, Fernando Henrique Sgarbi Parro ${ }^{2}$, Mariana Petaccia de Macedo ${ }^{1}$, Clovis Antonio \\ Lopes Pinto ${ }^{1}$
}

DOI: http:/ / dx.doi.org/10.1590/abd1806-4841.20198199

Abstract: Proliferating trichilemmal cyst is an uncommon neoplasm arising from the follicular isthmus, whose histopathological hallmark is the presence of trichilemmal keratinization. We describe a case of proliferating trichilemmal cyst in a 57-yearold woman with a broad clinical, radiological, macroscopic and microscopic correlation.

Keywords: Adnexal diseases; Cysts; Diagnostic imaging; Histology; Microscopy

\section{INTRODUCTION}

Proliferating trichilemmal cyst (PTC), also called proliferating pillar tumor, is a rare adnexal tumor, usually of benign behavior, which develops most often on the scalp of elderly women. A strong histological feature is the presence of a trichilemmal keratinization pattern associated with proliferating lobules of squamous epithelial cells. On rare occasions, a PTC may evolve to a malignant proliferating trichilemmal cyst. ${ }^{1,2} \mathrm{~A}$ few reports in the literature demonstrate clinical, radiological, and histopathological characteristics of these lesions. Herein, we report a case of a rapidly growing scalp PTC in a patient with an oncologic history of liposarcoma and previous cytological diagnosis of a lesion suggestive of pilomatrixoma. The aspects discussed in this paper includes the differential diagnosis, cytology role, anatomopathological evaluation, and adequate treatment of this entity.

\section{CASE REPORT}

A 57-year-old female patient from São Paulo, with a previous diagnosis of metastatic liposarcoma to the liver, was referred to our dermatology center reporting the appearance of a nodule on the right side of the scalp 1 month prior to the consultation, with local radiating pain towards the ipsilateral ear and face. On clinical examination, the scalp topography revealed a firm elevated nodular lesion of smooth surface in the right parietal region, measuring approximately $4.0 \mathrm{~cm}$. The skin was flexible and clear without phlogistic signs (Figure 1A). Ultrasound examination (USG) revealed a heterogeneous, well-delimited solid and cystic lesion with hyperechoic areas, measuring $38 \times 33 \times 34 \mathrm{~mm}$ (Figure 1B). Skull tomography showed that bone structures were not affected by the lesion. Differential diagnostic hypothesis included lipoma and liposarcoma metastasis, detected radiologically.

Initially, the patient underwent an ultrasound-guided fine-needle aspiration biopsy (FNAB) with cytology compatible with a squamous lesion suggestive of pilomatrixoma. Based on this cytological finding, she underwent complete surgical resection of the lesion. The scalp defect caused by tumor resection was repaired with local fasciocutaneous flaps and healing occurred without intercurrences. The patient had no recurrence until the last appointment, approximately 6 months after resection. Macroscopy revealed a solid and cystic lesion measuring $4.5 \times 4.0 \times 2.0 \mathrm{~cm}$, in contact with the dermis in its superficial portion and with a fascial layer at its base (Figure 2A). The open lesion revealed a cystic cavity with lumpy walls, brownish exudate, and a whitish solid nodular formation on one of the walls, measuring $1.0 \times 1.0 \mathrm{~cm}$ (Figure 2B). Microscopy revealed a localized cystic lesion in the subcutaneous tissue with an associated solid area. The cystic lesion presented a scaly coating with abrupt trichilemmal keratinization (Figure 3A). In the solid

\footnotetext{
Received 17 February 2018.

Accepted 15 May 2018

* Study conducted at the A.C. Camargo Cancer Center, São Paulo (SP), Brazil. Financial support: None.

Conflict of Interest: None.

1 Department of Pathology, A.C. Camargo Cancer Center, São Paulo (SP), Brazil.

2 Department of Surgery, A.C. Camargo Cancer Center, São Paulo (SP), Brazil.
}

MAILING AdDREss:
Ediel Valerio
E-mail: edielvaleriosf@gmail.com

(C2019 by Anais Brasileiros de Dermatologia 

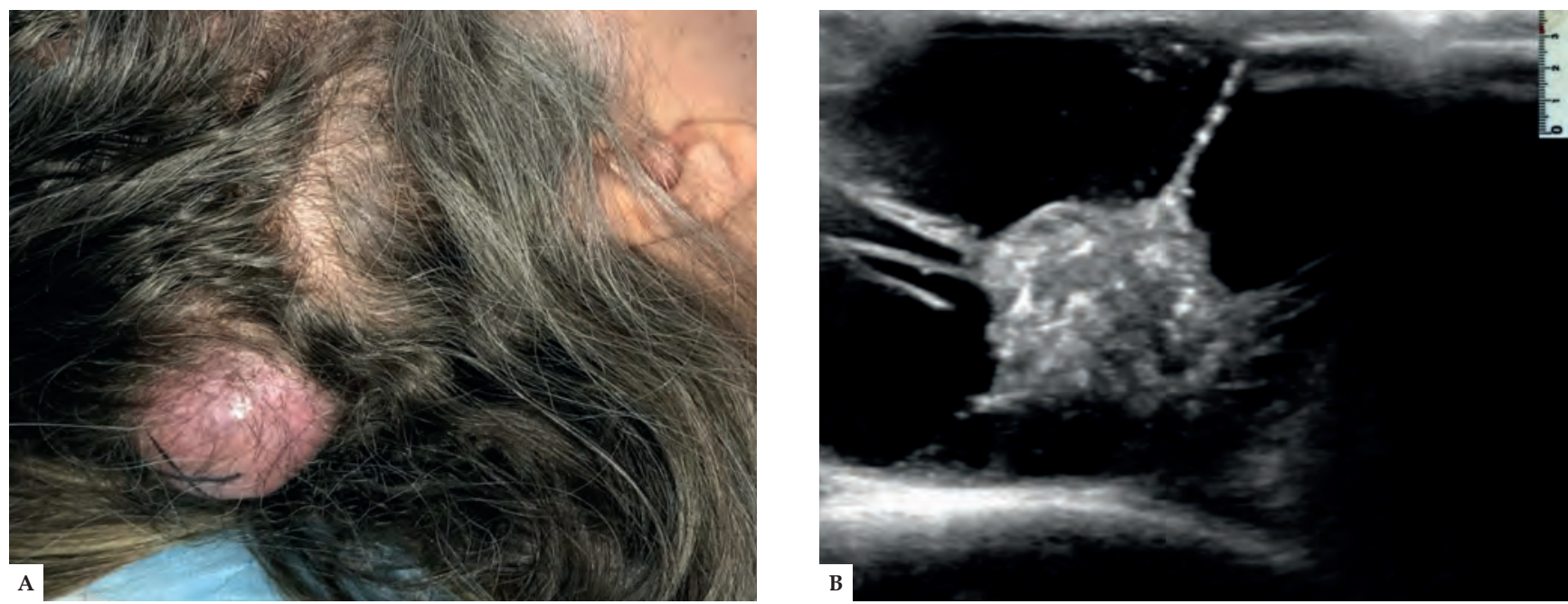

Figure 1: Clinical and imaging characteristics. A) Clinical examination evidencing a nodular lesion on the scalp, with a smooth surface and flexible skin, without abnormalities or phlogistic signs. B) Ultrasonography showing a cystic lesion with a heterogeneous solid area, in addition to hyperechoic areas
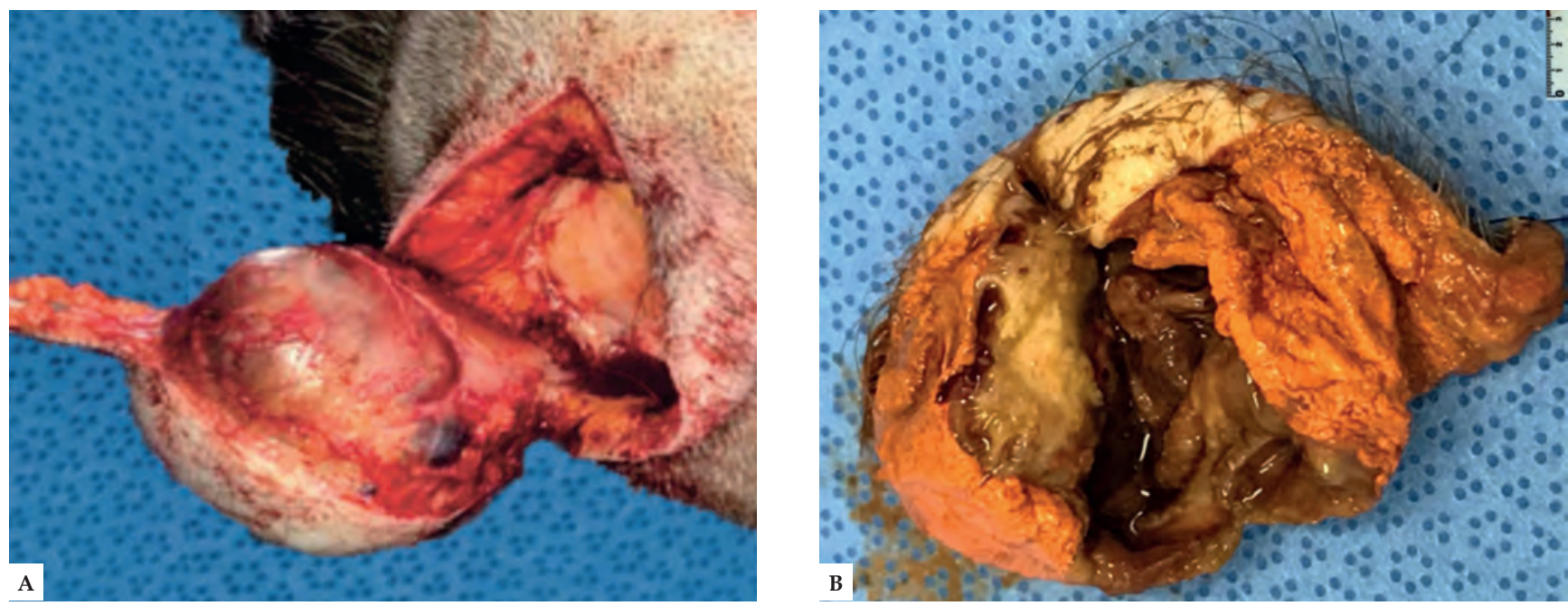

Figure 2: Perioperative characteristics. A) Intraoperative aspect of lesion resection. B) Macroscopic aspect of the specimen at cut surface evidencing a cystic cavity with brownish content and lumpy walls with a whitish solid area inside

area, a proliferation of multiple lobules of squamous epithelium without atypia was found, presenting only rare mitotic figures without invasion of adjacent tissues (Figure 3B). The final histopathological diagnosis was proliferating trichilemmal cyst.

\section{DISCUSSION}

We report a case of PTC with a broad correlation between clinical, radiological, macroscopic, and microscopic images. Proliferating pilar tumors were first recognized by Wilson-Jones in 1966. This neoplasm arises from the isthmic region of the hair follicle and is histologically characterized by the presence of trichilemmal keratinization, which corresponds to an abrupt transition from the spinal layer to the stratum corneum, with no intervening granular layer. ${ }^{1}$ The tumors may be solid or solid cystic, usually found in areas with a high concentration of hair follicles, such as the scalp. A common clinical picture of PTC is a subcutaneous nodule that progresses slowly to a large nodular mass. Cases of rapid growth may indicate malignant transformation to carcinoma. It often follows a history of trauma or inflammation. However, de novo mutations may also occur. ${ }^{2}$ In our case, the patient reported no history of trauma, and the lump grew in only one month. Histologically, CTP is composed of proliferating lobules of squamous epithelium, showing multiple central areas of trichilemmal keratinization and formation of homogeneous keratin cysts. ${ }^{1}$

It can be differentiated from its main differential diagnosis, squamous cell carcinoma, by the abrupt mode of keratinization, the presence of clear cells resulting in glycogen storage, and, most importantly, a sharp demarcation of the lesion without infiltration into adjacent structures. ${ }^{2}$ Other differential diagnoses include epidermoid cyst, keratoacanthoma, pilomatrixoma, sweat gland tumor, basal cell carcinoma, angiosarcoma, and trichilemmal carcinoma. ${ }^{3}$ Our patient was submitted to a cytological study by FNAB with a suggestive diagnosis of pilomatrixoma. Cytology gives good accuracy in determining the nature of lesions - squamous in our case. 

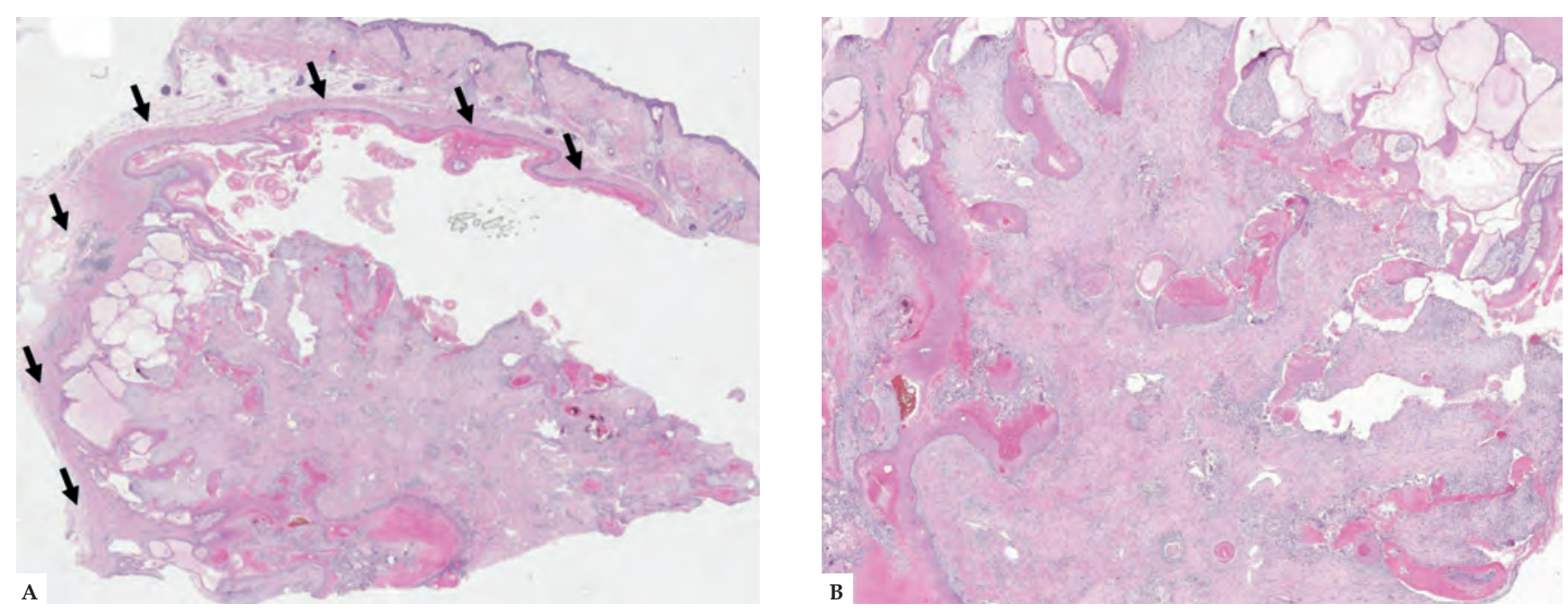

Figure 3: Microscopic appearance of the lesion by the Hematoxylin \& eosin staining. (A, x20) Panoramic photo showing cystic lesion (arrow) located in the subcutaneous tissue showing a scaly coating with trichilemmal keratinization (B, x40) characterizing the diagnosis of proliferating trichilemmal cyst. The squamous cell blocks in the proliferating component show no cytological atypias

However, the evaluation of the presence of a proliferating component associated with the lesion depends on histopathological examination.

Malignant transformation of PTC to trichilemmal carcinoma can occur. It is diagnosed by the presence of extensive areas of squamous component with cytological atypias, cellular pleomorphism with atypical mitoses, dyskeratotic cells, and infiltrative margins with adjacent tissue invasion. ${ }^{4-6}$ Despite the rapid growth of the lesion described in our case, histologically, we observed no significant cytological atypias or tissue invasiveness for the diagnosis of carcinoma. Complete local excision of the lesion is the treatment of choice for PTC, and some authors suggest a $1.0 \mathrm{~cm}$ margin due to the possibility of recurrence. ${ }^{7}$ Although our patient had a previous oncological diagnosis of metastatic liposarcoma, we found no association of the development of trichilemmal lesions with liposarcoma in the literature. In summary, PTC is an unusual histopathological entity that makes a broad differential diagnosis with other adnexal and epidermal tumors, and may eventually follow an aggressive clinical course. Thus, careful histopathological evaluation of cutaneous lesions is imperative. $\square$

\section{REFERENCES}

1. Ramaswamy AS, Manjunatha HK, Sunilkumar B, Arunkumar SP. Morphological Spectrum of Pilar Cysts. N Am J Med. 2013;5:124-8.

2. Alam K, Gupta K, Maheshwari V, Varshney M, Jain A, Khan AH. A large proliferating trichilemmal cyst masquerading as squamous cell carcinoma. Indian J Dermatol. 2015;60:104.

3. Peryassu MA, Peryassu BC, Peryassu RC, Piñeiro-Maceira J, RamosE-Silva M. Proliferating trichilemmal tumor: a case on the nose of a 70-year-old man. Case Rep Dermatol. 2013;5:248-53.

4. Goyal S, Jain BB, Jana S, Bhattacharya SK. Malignant Proliferating Trichilemmal Tumor. Indian J Dermatol. 2012;57:50-2.
5. Saida T, Oohara K, Hori Y, Tsuchiya S. Development of a malignant proliferating trichilemmal cyst in a patient with multiple trichilemmal cysts. Dermatologica. 1983;166:203-8.

6. Kim UG, Kook DB, Kim TH, Kim CH. Trichilemmal Carcinoma from Proliferating Trichilemmal Cyst on the Posterior Neck. Arch Craniofac Surg. 2017;18:50-3.

7. Rangel-Gamboa L, Reyes-Castro M, Dominguez-Cherit J, Vega-Memije E. Proliferating trichilemmal cyst: the value of ki67 immunostaining. Int J Trichology. 2013;5:115-7.

\footnotetext{
AUTHORS' CONTRIBUTIONS

$\begin{array}{lll}\text { Ediel Valerio } & \text { (iD) ORCID 0000-0001-9546-8404 }\end{array}$

Approval of the final version of the manuscript; Conception and planning of the study; Elaboration and writing of the manuscript; Obtaining, analyzing and interpreting the data; Critical review of the literature

\section{Fernando Henrique Sgarbi Parro $\quad$ (iD) ORCID 0000-0002-2384-6549}

Approval of the final version of the manuscript; Conception and planning of the study; Effective participation in research orientation; Intellectual participation in propaedeutic and/or therapeutic conduct of the cases studied; Critical review of the manuscript

Mariana Petaccia de Macedo $\quad$ (iD) ORCID 0000-0002-0434-7605

Approval of the final version of the manuscript; Conception and planning of the study; Effective participation in research orientation; Intellectual participation in propaedeutic and/or therapeutic conduct of the cases studied; Critical review of the manuscript

\section{Clovis Antonio Lopes Pinto $\quad$ (iD) ORCID 0000-0003-1711-0081}

Approval of the final version of the manuscript; Conception and planning of the study; Effective participation in research orientation; Intellectual participation in propaedeutic and/or therapeutic conduct of the cases studied; Critical review of the manuscript
}

How to cite this article: Valerio E, Parro FHS, Macedo MP, Pinto CAL. Proliferating trichilemmal cyst with clinical, radiological, macroscopic, and microscopic correlation. An Bras Dermatol. 2019;94(4):452-4. 